\title{
LIXIVIAÇÃO DO HERBICIDA 2,4-D + PICLORAM EM LATOSSOLO VERMELHO- AMARELO Distrófico
}

Mauricio Franceschi ${ }^{1}$, Ricardo Adriano Felito ${ }^{2}$, Oscar Mitsuo Yamashita ${ }^{3}$, Juliano Lorenzon ${ }^{1}$, Marco Antonio Camillo de Carvalho ${ }^{3}$

${ }^{1}$ Graduando em Agronomia, Universidade do Estado de Mato Grosso Alta Floresta, MT, Brasil (mauriciofranceschi123@hotmail.com)

${ }^{2}$ Mestrando do Programa de Pós-graduação em Biodiversidade e Agroecossistemas Amazônicos, Universidade do Estado de Mato Grosso, Alta Floresta, MT, Brasil

${ }^{3}$ Professor do Programa de Pós-graduação em Biodiversidade e Agroecossistemas Amazônicos, Universidade do Estado de Mato Grosso, Alta Floresta MT, Brasil

Recebido em: 08/09/2015 - Aprovado em: 14/11/2015 - Publicado em: 01/12/2015 DOI: http://dx.doi.org/10.18677/Enciclopedia_Biosfera_2015_188

\section{RESUMO}

O presente trabalho teve como objetivo determinar a lixiviação de doses crescentes do herbicida 2,4-D + picloram em LATOSSOLO VERMELHO AMARELO Distrófico utilizando a soja como espécie bioindicadora. Para isso, amostras desse solo foram usadas como substrato para preenchimento de tubos de PVC com $10 \mathrm{~cm}$ de diâmetro e $50 \mathrm{~cm}$ de comprimento. Os tratamentos compreenderam na combinação de cinco doses $0 ; 1 ; 0,5 ; 0,25 ; 0,125 \%$ de um litro do produto Tordon $^{\circledR}$, e seis profundidades de amostragem nas colunas $(0,8,16,24,32,40 \mathrm{~cm})$. Foram analisadas as seguintes variáveis: fitointoxicação, altura, comprimento radicular, área foliar e matéria seca. Realizou-se o experimento em delineamento inteiramente casualizado, com quatro repetições. Concluiu-se que há lixiviação do herbicida 2,4-D + picloram até $32 \mathrm{~cm}$ de profundidade em LATOSSOLO VERMELHO-AMARELO Distrófico, sendo que maiores concentrações do herbicida provocam maiores efeitos tóxicos em plantas de soja, mesmo em maiores profundidades.

PALAVRAS-CHAVE: contaminação, fitointoxicação, movimentação de herbicida, Tordon.

\section{LEACHING OF THE HERBICIDE 2,4-D + PICLORAM LATOSOL RED-OXISOL Dystrophic}

\section{ABSTRACT}

This study aimed to determine the leaching of increasing doses of the herbicide 2,4$\mathrm{D}+$ picloram in Dystrophic Red Yellow Latosol using soy as bio-indicator species. For this, samples of this soil were used as a substrate for filling PVC tubes $10 \mathrm{~cm}$ in diameter and $50 \mathrm{~cm}$ long. The treatments consisted of the combination of five doses $0 ; 1 ; 0.5 ; 0.25 ; 0.125 \%$ Tordon $^{\circledR}$ one liter of product, six sampling depths in columns $(0,8,16,24,32,40 \mathrm{~cm})$. The following variables were analyzed: phytotoxicity, height, root length, leaf area and dry matter. He carried out the experiment in a completely 
randomized design with four replications. It follows that there leaching of the herbicide 2,4-D + picloram up to $32 \mathrm{~cm}$ depth in oxisol dystrophic; highest herbicide concentrations cause major toxic effects on cucumber plants, even at greater depths.

KEYWORDS: contamination, plant injury, herbicide handling, Tordon.

\section{INTRODUÇÃO}

A pecuária bovina é um dos setores mais importantes do agronegócio brasileiro e consequentemente da economia nacional. A base dessa sustentação é a pastagem, visto que grande parte da criação bovina é realizada em extensas áreas de forrageiras. Esta é a forma mais econômica e prática de produzir e oferecer alimentos para os aninais (DIAS FILHO, 2011).

Porém, em consequência do manejo inadequado do solo por diversas décadas de exploração, o que se tem verificado na pratica é a predominância de pastagens degradadas (DIAS-FILHO, 2014). A falta de manutenção da fertilidade do solo, ausência de controle de pragas, doenças e plantas daninhas e o excesso de lotação, tornam a pastagem degradada, promovendo elevados prejuízos. As plantas daninhas competem por água, luz, nutrientes e espaço físico, causando a redução na capacidade de lotação animal (PAULINO et al., 2012).

O controle das plantas daninhas é um dos fatores indispensáveis para melhoria dos índices de produtividade da atividade agropecuária. O controle pode ser realizado de diversas formas, entre eles o método químico é o mais utilizado devido seu baixo custo e eficácia (PELLEGRINI et al., 2010).

Os herbicidas do grupo das auxinas sintéticas têm sido um dos mais usados no controle de plantas daninhas dicotiledôneas em forrageiras (BRAGA, 2013). Dentre os herbicidas deste grupo, o 2,4-D (ácido 2,4-diclorofenoxiacético) e o picloram (ácido 4-amino 3,5,6 tricloro-2-piridinacarboxílico) compõem a maioria dos produtos registrados para aplicação na agricultura (BRASIL, 2013).

Destes, o picloram tem despertado a atenção pela eficiência em provocar a morte de dicotiledôneas de difícil controle que se desenvolvem em áreas de pastagens. O produto te como característica a baixa sorção nos coloides do solo, alta solubilidade em água e elevado potencial de lixiviação (D'ANTONINO et al., 2009). Apresenta como principal problema a possibilidade de contaminação de organismos não alvo, podendo causar intoxicação em espécies dicotiledôneas sensíveis tais como a soja, feijão, algodão dentre outras dicotiledôneas, quando cultivadas em sucessão (SILVA et al., 2007) e a contaminação ambiental ocasionada por sua lixiviação para camadas mais profundas no perfil do solo, podendo atingir cursos de águas (SANTOS et al., 2006).

A utilização correta e consciente dos herbicidas é muito importante, pois o setor agrícola tem sido questionado e julgado do ponto de vista ambiental. Buscando-se encontrar formas de reduzir o risco do impacto ambiental que o efeito residual de herbicida possa vir a causar, além de minimizar problemas de fitointoxicação e perdas em culturas subsequentes, diversos estudos têm sido realizados especialmente para compreender o comportamento desses produtos no solo (SANTOS et al., 2013).

O processo de lixiviação é a principal forma de transporte no solo das moléculas não-voláteis e solúveis em água. Essas moléculas deslocam-se no perfil do solo acompanhando o fluxo de água (PRATA et al., 2003; POSSAMAI, 2012). Esse processo é dependente das características do herbicida, das características e propriedades do solo e das condições climáticas (CARVALHO, 2015). 
No entanto, é fundamental que estes compostos químicos sejam adequadamente aplicados, para que seja preservada a qualidade final dos produtos colhidos, assim como dos recursos naturais que sustentam a produção, especialmente o solo e água (SILVA et al., 2007).

Em estudos sobre atividade de moléculas herbicidas nos solos pesquisadores têm utilizado o bioensaio, que alia baixo custo a bom resultado prático. Essa técnica consiste em utilizar plantas sensíveis aos produtos testados, fazendo com que os resíduos dos herbicidas ou soluções presentes no solo possam ser evidenciados por meio da alteração das características agronômicas da planta-teste (MELO et al., 2010; MANCUSO et al., 2011).

Diante do exposto, objetivou-se determinar a lixiviação do herbicida 2,4-D + picloram em LATOSSOLO VERMELHO AMARELO Distrófico após chuva simulada de $40 \mathrm{~mm}$ nas dosagens de 0,125; 0,25; 0,5 e $1 \%$.

\section{MATERIAL E MÉTODOS}

\section{Procedimentos metodológicos}

O estudo foi conduzido e desenvolvido em ambiente protegido da Universidade do Estado de Mato Grosso, localizado no município de Alta Floresta, situada no norte do estado, nas coordenadas 0952' 1" de latitude Sul e 56066'41" de longitude Oeste, com altitude de $280 \mathrm{~m}$ acima do nível do mar.

O solo foi coletado em área de mata virgem em uma chácara no bairro Jardim Panorama na região de Alta Floresta, onde segundo históricos não havia aplicações de herbicidas na área. A amostra foi submetida à análise físico - química (Tabela 1). O solo foi classificado como LATOSSOLO VERMELHO-AMARELO Distrófico (EMBRAPA, 2013).

TABELA 1. Análises realizadas no Laboratório de solos e análise foliar - LASAF da Universidade do Estado de Mato Grosso Campus Universitário de Alta Floresta MT, segundo metodologia indicada pela Empresa Brasileira de Pesquisa Agropecuária EMBRAPA SOLOS. 2015.

\begin{tabular}{|c|c|c|c|c|c|c|c|c|}
\hline \multicolumn{9}{|c|}{ Análise granulométrica (\%) } \\
\hline \multicolumn{2}{|r|}{ Areia } & \multicolumn{4}{|c|}{ Silte } & \multicolumn{3}{|c|}{ Argila } \\
\hline \multicolumn{2}{|r|}{42,1} & \multicolumn{3}{|c|}{4,1} & & \multicolumn{3}{|c|}{53,8} \\
\hline \multicolumn{9}{|c|}{ Análise química } \\
\hline $\mathrm{pH}$ & $\mathrm{K}+$ & $\mathrm{Ca}^{+2}$ & $\mathrm{Mg}^{+2}$ & $\mathrm{Al}^{+3}$ & $\mathrm{H}+\mathrm{Al}$ & $\begin{array}{c}\text { CTC } \\
\text { Efetiva }\end{array}$ & $\begin{array}{c}\text { CTC } \\
\text { Potencial }\end{array}$ & V \\
\hline $\mathrm{H}_{2} \mathrm{O}$ & $\mathrm{mg} \mathrm{dm} \mathrm{m}^{-3}$ & \multicolumn{6}{|c|}{$\mathrm{cmol}_{\mathrm{c}} \mathrm{dm}^{-3}$} & $\%$ \\
\hline 5,3 & $1,7 \quad 40,6$ & $\overline{1,1}$ & 0,5 & 0,3 & 4,4 & 2,0 & 6,1 & $\overline{27,8}$ \\
\hline
\end{tabular}

Para a montagem do experimento foram utilizados tubos de PVC de $10 \mathrm{~cm}$ de diâmetro e $50 \mathrm{~cm}$ de comprimento, onde foram cortados longitudinalmente, parafinados internamente para evitar o escorrimento lateral da água após a simulação da chuva e posteriormente a base de cada coluna foi fechada, para evitar perda do material. Para serem mantidas na posição vertical as colunas foram mantidas sobre estrados acondicionadas em caixas de madeira e posteriormente, cada uma foi preenchida com solo já umedecido, próximo a capacidade de campo.

O herbicida 2,4-D + Picloram foi aplicado nas doses de $1 ; 0,5 ; 0,25 ; 0,125 \%$ da dose recomendada de um litro do produto Tordon ${ }^{\circledR}$ para pastagem. As aplicações 
foram realizadas de forma individual na superfície de cada tubo (posicionado na vertical), simulando volume de calda de 300 litros por ha, onde através de pulverizador de pressão constante procedeu-se a aplicação de forma uniforme. Após 24 horas, foi realizada a simulação de chuva de $40 \mathrm{~mm}$, mantendo-se os tubos por um período de 48 horas na posição vertical para que ocorresse a percolação.

Após esse período, os tubos foram colocados na posição horizontal, retirada a tampa lateral e posteriormente feita o corte do solo excedente. A semeadura ocorreu logo em seguida, nas profundidades de $0,8,16,24,32,40 \mathrm{~cm}$ sendo semeadas 3 sementes de soja (Glycine max L.) por linha, sendo esta utilizada como planta bioindicadora. $O$ ensaio foi conduzido por um período de15 dias.

\section{Variáveis}

Após 15 dias da semeadura, as plantas foram submetidas à análise das seguintes variáveis:

Fitointoxicação: Para análise foram consideradas notas de 0 a 10, sendo que a nota 0 foi atribuída às plantas de soja (Glycine max L.) com ausência de sintomas e 10 para a morte das mesmas.

Altura: Com auxílio de uma régua graduada foi determinado o comprimento da planta de soja (Glycine max L.), sendo considerada sua altura desde o colo até o meristema apical.

Comprimento radicular: Para determinar o comprimento de raiz, as plantas de soja (Glycine max L.) foram cuidadosamente retiradas dos recipientes sob de água corrente e levadas ao laboratório, e posteriormente mensurado, com o uso de régua graduada.

Área foliar: Para análise de área foliar, foram retiradas somente as folhas verdadeiras sendo assim calculadas através do equipamento de área foliar (LI-3100 Area Meter ${ }^{\circledR}$ ).

\section{Análise estatística}

Os dados obtidos foram submetidos à análise de variância pelo teste $\mathrm{F}$ e as medias comparadas pelo teste Tukey ao nível $5 \%$ de probabilidade, havendo significância para os fatores quantitativos, foram confeccionados gráficos de regressão. As análises estatísticas foram realizadas com auxílio do software estatístico SISVAR (FERREIRA, 2011).

\section{RESULTADOS E DISCUSSÃO}

Ao analisar intoxicação das plantas de soja, verificou que a presença do herbicida causou níveis de intoxicação superior aos $90 \%$ independente das dosagens utilizadas até os $8 \mathrm{~cm}$ de profundidades. Na utilização da menor dose verificou níveis de intoxicação até aos $32 \mathrm{~cm}$ de profundidade, sendo que nas demais dosagens utilizadas verificou a presença do herbicida em toda a coluna (Figura 1).

$\mathrm{Na}$ utilização da menor dose $(0,125 \%)$ os níveis de intoxicação foram de 8,75 ; 2,63 e 0,68 nas profundidades de 16;24 e $32 \mathrm{~cm}$ respectivamente, no entanto conforme houve o aumento na dosagem utilizada, os níveis de intoxicação chegaram a 9; 8,5 e 7 em profundidades de 16; 24 e $32 \mathrm{~cm}$ utilizando doses de $1 \%$.

Esses resultados são semelhantes aos observados por D'ANTONINO et al. (2009), que ao estudar a lixiviação do picloram em solos com pH de 4,9 e posteriormente submetidos a chuva simulada de $40 \mathrm{~mm}$, observou elevada 
intensidade dos sintomas nas plantas cultivadas na parte superior da coluna (superior a $90 \%$ nos primeiros $5 \mathrm{~cm}$ de profundidade), sendo que essa intensidade foi decrescente até $35 \mathrm{~cm}$ de profundidade, no entanto, observou-se níveis de intoxicação em toda coluna.

Os níveis de intoxicação foram decrescentes com 0 aumento da profundidade. Utilizando doses menores como 0,125 e $0,25 \%$ os níveis de intoxicação em profundidades de 24 e $32 \mathrm{~cm}$ foram relativamente baixos. No entanto, na utilização de doses maiores como a de 0,5 de $1 \%$ os níveis de intoxicação mantiveram-se altos mesmo nas profundidades de 24 e 32 cm respectivamente.

Dentre os sintomas de fitointoxicação, a epinastia das folhas, o retorcimento do caule e fortes alterações na altura foram os mais observados entre as plantas jovens, especialmente nas maiores doses estudadas e nas menores profundidades. Resultados semelhantes foram relatados por OLIVEIRA JÚNIOR et al. (2007), estudando o efeito de 2,4-D em subdoses nas plantas de uva, no município de Maringá-PR, onde verificaram que os sintomas mais evidentes na cultura da uva foram o alongamento das gavinhas, epinastia das folhas e deformações de ramos jovens e de folhas. Também, CONSTANTIN et al. (2007), na mesma época e região do estudo anterior, verificaram encarquilhamento das folhas mais novas de plantas de algodão tratado com doses reduzidas de 2,4-D.
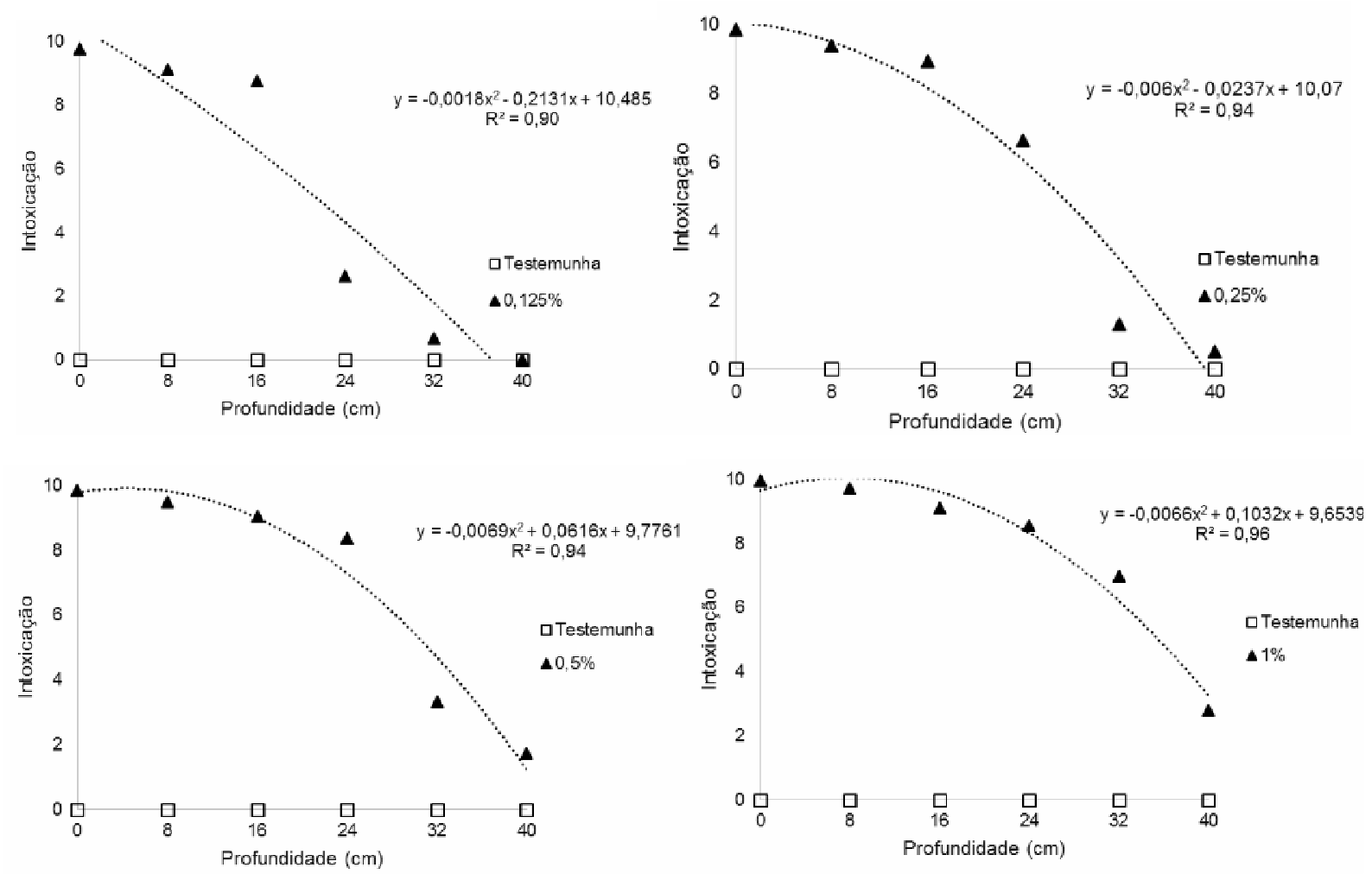

FIGURA 1. Intoxicação das plantas de soja cultivadas em diferentes profundidades e doses de 2,4-D + picloram. Alta Floresta, MT. 2015. A: testemunha comparada com 0,125\% da dose (1,0 L do herbicida); B: 0,25\%; C: 0,5\% e D: $1 \%$.

Ao analisar altura de planta observa-se que já na menor dose estudada as plantas cultivadas na profundidade zero houve inibição da germinação e que só aos $24 \mathrm{~cm}$ de profundidade as plantas não se diferenciaram significativamente das ENCICLOPÉDIA BIOSFERA, Centro Científico Conhecer - Goiânia, v.11 n.22; p. 2155 
testemunhas. Nas dosagens de 0,5 e 1\% não ocorreram germinação das sementes de soja quando cultivadas nas profundidades de até $16 \mathrm{~cm}$.

Em relação à testemunha, aos 32 centímetros de profundidade, as doses 0,125 e $0,25 \%$ provocaram aumento na altura de plantas, no entanto, nas doses de 0,5 e $1 \%$ as plantas apresentaram efeito contrário devido às altas concentrações do herbicida, sofrendo redução na altura (Figura 2).

Aos $40 \mathrm{~cm}$ de profundidade, com exceção da menor dose utilizada $(0,125 \%)$ verificou-se aumento na altura das plantas, comparando-se com as das testemunhas, indicando assim, a presença do herbicida ao longo de toda coluna. Esses resultados concordam com os obtidos por FARINELLI et al. (2005), que observaram maiores alturas das plantas de milheto, em relação às plantas não tratadas com 2,4-D. YAMASHITA et al. (2009) também verificaram que o herbicida 2,4-D, na dose de $335 \mathrm{~g}$ e.a. ha $^{-1}$ em Ceiba pentandra provocou aumento na altura de plantas. Essa alteração morfológica, caracterizada pela concentração de auxina nos ramos mais jovens, é um efeito característico dos herbicidas auxínicos (DEUBER, 1992).

Herbicidas que pertencem ao grupo dos mimetizadores de auxinas ou reguladores de crescimento, tais como os utilizados no presente estudo, atuam provocando distúrbios no metabolismo dos ácidos nucleicos, aumentando assim a atividade enzimática e a destruição do floema bem como causando alongamento celular, turgescência e rompimento das células (CARMO et al., 2008).
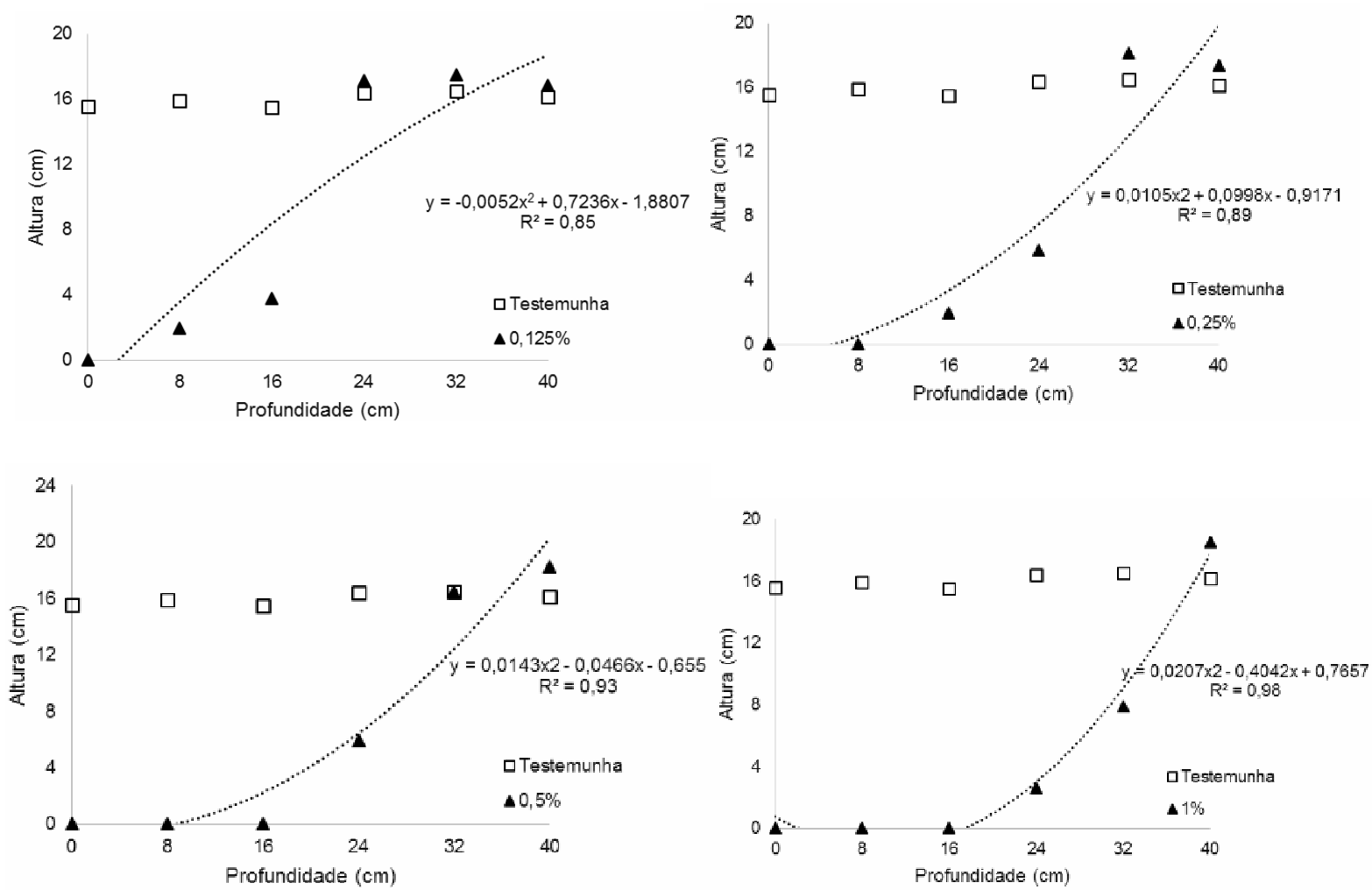

FIGURA 2. Altura das plantas de soja cultivadas em diferentes profundidades e doses de 2,4-D + picloram. Alta Floresta, MT. 2015. A: testemunha comparada com 0,125\% da dose (1,0 L do herbicida); B: 0,25\%; C: 0,5\% e D: $1 \%$.

Ao analisar comprimento radicular de plantas de soja observou-se redução no crescimento radicular em todas as doses aplicadas, até na profundidade de $16 \mathrm{~cm}$. 
Na menor dose estudada $(0,125 \%)$, as plantas nas profundidades entre 0,8 e $16 \mathrm{~cm}$ tiveram o desenvolvimento radicular reduzido em 100; 91 e $81 \%$, respectivamente, quando comparadas à testemunha. Já na maior dose utilizada não houve desenvolvimento de raízes nas mesmas profundidades (Figura 3). Possivelmente, isso se deve ao aumento da enzima celulase nas raízes, levando à rápida destruição do sistema radicular (THILL, 2003).

Ao se utilizar doses de 0,125\% verificou-se que a partir dos $24 \mathrm{~cm}$ de profundidade o comprimento de raiz não de diferenciou significativamente das da testemunha. No entanto ao se utilizar dosagem de 0,5 e $1 \%$ as plantas sofreram forte redução no comprimento radicular mesmo em maiores profundidades.
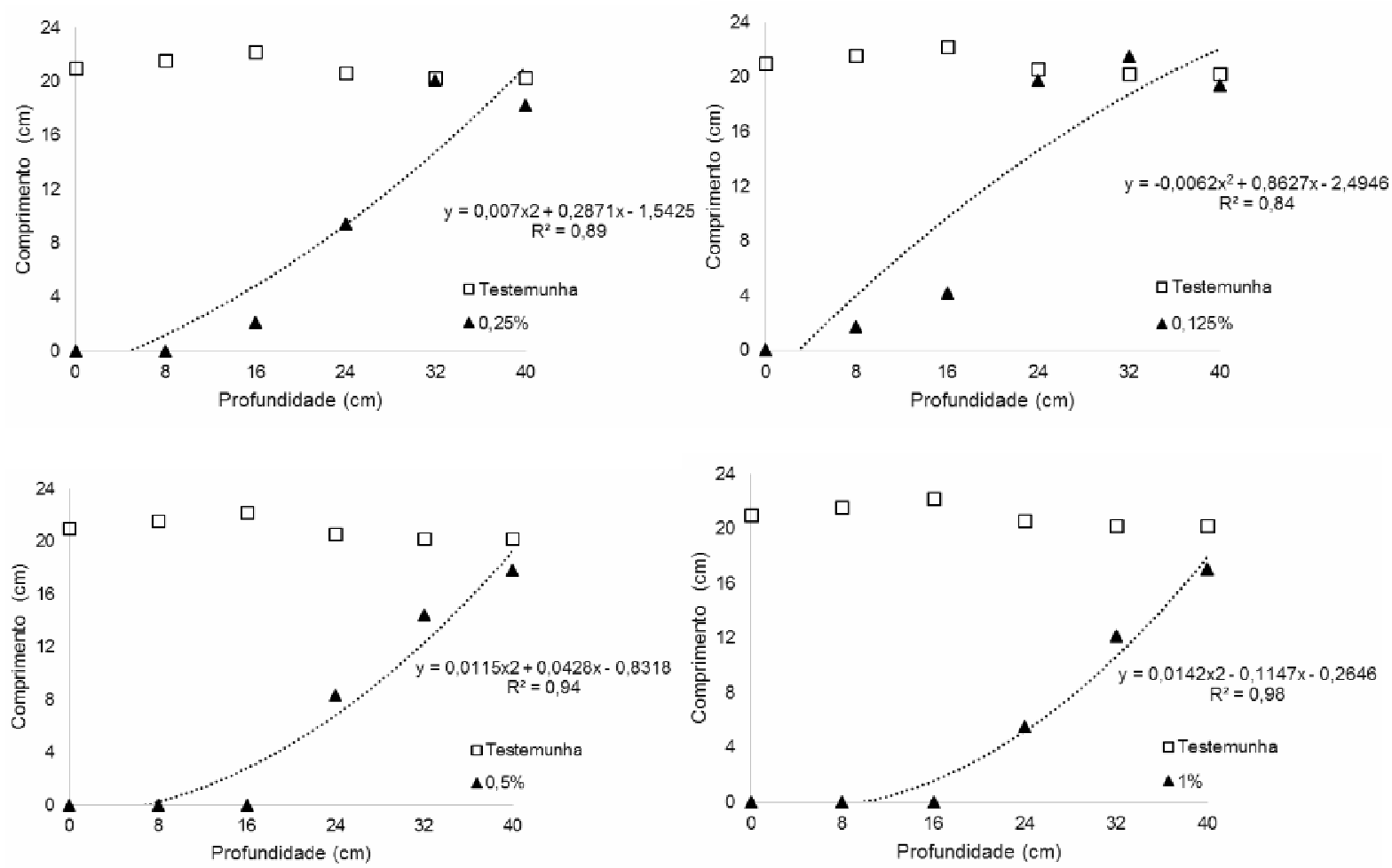

FIGURA 3. Comprimento das raízes de soja cultivadas em diferentes profundidades e doses de 2,4-D + picloram. Alta Floresta, MT. 2015. A: testemunha comparada com $0,125 \%$ da dose ( $1,0 \mathrm{~L}$ do herbicida); B: $0,25 \%$; C: $0,5 \%$ e D: $1 \%$.

\section{Área foliar}

A lixiviação do 2,4-D + picloram através das colunas de solo foi influenciada conforme a dosagem utilizada. Verificou-se que ao se analisar área foliar das plantas de soja, o herbicida deslocou-se até $32 \mathrm{~cm}$ de profundidade nas duas menores doses estudadas $(0,125$ e $0,25 \%)$, e chegando aos $40 \mathrm{~cm}$ nas demais dosagens. Observou-se também que, com exceção da menor dose estudada, nenhuma planta apresentou crescimento de folha verdadeira até os $24 \mathrm{~cm}$ de profundidade (Figura 4). 
Segundo OLIVEIRA \& BRIGHENTI (2011), herbicidas de caráter ácidos como o picloram e o 2,4-D, que tem sua capacidade de dissociação eletrolítica (pKa) igual a 2,3 e 2,8 respectivamente, $\mathrm{o}$ pH é um dos fatores determinantes no comportamento desses produtos no solo, uma vez que determina a forma iônica predominante na solução. Como o solo estudado tem o pH é maior que o pKa do herbicida, a concentração da forma não dissociada (molecular) é menor que a da forma aniônica, ou seja, o herbicida ficando na forma aniônica, tem mais chances de ser transportados livremente através da solução do solo, justificando a presença do herbicida ao longo da coluna.
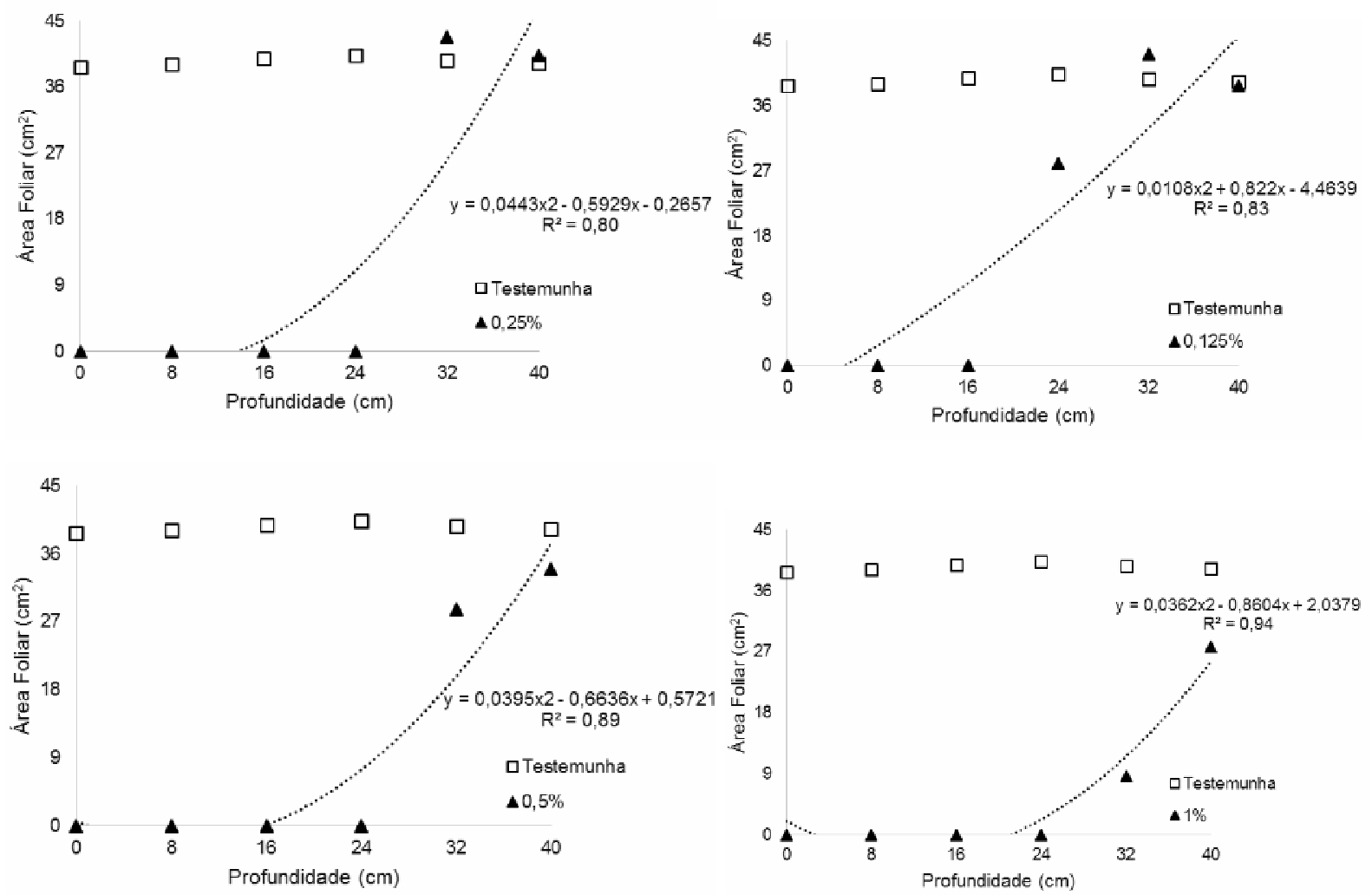

FIGURA 4. Área foliar das plantas de soja cultivadas em diferentes profundidades e doses de 2,4-D + picloram. Alta Floresta, MT. 2015. A: testemunha comparada com $0,125 \%$ da dose ( $1,0 \mathrm{~L}$ do herbicida); B: $0,25 \%$; C: $0,5 \%$ e D: $1 \%$.

A mobilidade do herbicida no solo pode alterar a sua capacidade e eficiência no controle de plantas daninhas e, principalmente a sua dissipação no ambiente (SILVA et al., 2007). Assim, estudos dessa natureza se constituem uma importante e relevante contribuição para avaliar os impactos ambientais destes produtos e seus efeitos futuros. 


\section{CONCLUSÃO}

Concluiu-se que há lixiviação do herbicida 2,4-D + picloram até $32 \mathrm{~cm}$ de profundidade em LATOSSOLO VERMELHO-AMARELO Distrófico, sendo que maiores concentrações do herbicida provocam maiores efeitos tóxicos em plantas de soja, mesmo em maiores profundidades.

\section{REFERÊNCIAS}

BRAGA, R.R.; COSTA, S.S.D. da; FERREIRA, E.A.; SANTOS, J.B. dos; SILVA, D.V. Atividade microbiana de solos contaminados com picloram e cultivados com Urochloa brizantha. Enciclopédia Biosfera, Goiânia, v. 9, n. 17, p. 302-314, 2013.

BRASIL. 2013. Ministério da Agricultura, Pecuária e Abastecimento. CoordenaçãoGeral de Agrotóxicos e Afins. Disponível em: $<$.http://extranet.agricultura.gov.br/agrofit_cons/principal_agrofit_cons>. Acesso em: 8 de abril de 2013.

CARMO, M.L.; PROCOPIO, S.O.; PIRES, F.R.; CARGNELUTTI FILHO, A.; BRAZ, G.B.P.; SILVA, W.F.P.; BARROSO, A.L.L.; SILVA, G.P.; CARMO, E.L.; BRAZ, A.J.B.P.; ASSIS, R.L. Influência do período de cultivo de Panicum maximum (cultivar tanzânia) na fitorremediação de solo contaminado com picloram. Planta Daninha, Viçosa, v. 26, n. 2, p. 315-322, 2008.

CARVALHO, L.B. Herbicidas. Lages: Ed. do autor. 2013. 62 p. Disponível em: $<$ https://leonardobcarvalho.files.wordpress.com/2013/02/livroherbicidas.pdf>. Acesso em: 23 fev. 2015.

CONSTANTIN, J.; OLIVEIRA JÚNIOR, R.S.; FAGLIARI, J.R.; PAGLIARI, P.H.; ARANTES, J.G.Z.; CAVALIERI, S.D.; FRAMESQUI, V.P.; GONÇALVES, D.A. Efeito de subdoses de 2,4-D na produtividade do algodão e suscetibilidade da cultura em função de seu estádio de desenvolvimento. Engenharia Agrícola, Jaboticabal, v.27, n.esp., p. 24-29, 2007.

D'ANTONINO, L.; SILVA, A.A.; FERREIRA, L.R.; CECON, P.R.; FRANÇA, A.C.; SILVA, G.R. Lixiviação do picloram em Argissolo-Vermelho Amarelo e Latossolo Vermelho-Amarelo com diferentes valores de pH. Planta Daninha, Viçosa, v. 27, n. 3, p. 589-600, 2009.

DEUBER, R. Ciência das plantas daninhas: fundamentos. Jaboticabal: FUNEP, 1992. $431 \mathrm{p}$.

DIAS-FILHO, M.B. Diagnóstico das pastagens no Brasil - Belém: Embrapa Amazônia Oriental, 2014. 36 p.

DIAS-FILHO, M.B. Degradação de pastagens: processos, causas e estratégias de recuperação. 4. ed. rev. atual. ampl. Belém: Ed. do Autor, 2011. 216 p.

Empresa Brasileira de Pesquisa Agropecuária - EMBRAPA. Sistema brasileiro de classificação de solos. 3.ed. Brasília, 2013. 353 p. 
FARINELLI, R.; PENARIOL, F.G.; LEMOS, L.B. Eficiência do herbicida 2,4-D no controle de Raphanus raphanistrum L., em pós-emergência na cultura de milheto. Revista Brasileira de Milho e Sorgo, Sete Lagoas, v. 4, n. 1, p. 104-111, 2005.

FERREIRA, D.F. Sisvar: a computer statistical analysis system. Ciência e Agrotecnologia, Lavras, v. 35, n. 6, p. 1039-1042, 2011.

MANCUSO, M.A.C.; NEGRISOLI, E.; PERIM, L. Efeito residual de herbicidas no solo ("Carryover"). Revista Brasileira de Herbicidas, Guarapuava, v.10, n.2, p.151-164, 2011.

MELO, C.A.D.; MEDEIROS, W.N.; TUFFI SANTOS, L.D.; FERREIRA, F.A.; TIBURCIO, R.A.S.; FERREIRA, L.R. Lixiviação de sulfentrazone, isoxaflutole e oxyfluorfen no perfil de três solos. Planta Daninha, Viçosa, v. 28, n. 2, p. 385-392, 2010.

OLIVEIRA, M. F.de; BRIGHENTI, A. M. Comportamento dos herbicidas no ambiente. In: OLIVEIRA JR. R. S.; CONSTANTIN. J.; INOUE. M. H. (Eds.). Biologia e manejo de plantas daninhas. Curitiba: Omnipax, 2011. p. 263-304.

OLIVEIRA JÚNIOR, R.S.; CONSTANTIN, J.; BRANDÃO FILHO, J.U.T.; CALLEGARI, O.; PAGLIARI, P.H.; CAVALIERI, S.D.; FRAMESQUI, V.P.; CARREIRA, S.A.M.; ROSO, A.C. Efeito de subdoses de 2,4-D na produtividade de uva itália e suscetibilidade da cultura em função de seu estádio de desenvolvimento. Engenharia Agrícola, Jaboticabal, v. 27, n.esp., p. 35-40, 2007.

PAULINO, V.T.; SCHUMANN, A.M.; SILVA, S.C.; RASQUINHO, N.M.; SANTOS, K.M. Impactos ambientais da exploração pecuária em sistemas intensivos de pastagem. Informe Agropecuário, Belo Horizonte, v.33, n.266, p.17-24, 2012.

PELLEGRINI, L.G.; NABINGER, C.; NEUMANN, M.; CARVALHO, P.C.F.; CRANCIO, L.A. Produção de forragem e dinâmica de uma pastagem natural submetida a diferentes métodos de controle de espécies indesejáveis e à adubação. Revista Brasileira de Zootecnia, v. 39, n. 11, p. 2380-2388, 2010.

POSSAMAI, A.C.S. Potencial de lixiviação dos herbicidas diuron e (diuron + hexazinone + sulfometuron) em solos com texturas contrastes. 2012. 38 p. Dissertação (Mestrado em Produção Vegetal) - Unidade Universitária de Aquidauana, Universidade do Estado de Mato Grosso do Sul, Aquidauana, 2012.

PRATA, F.; CARDINALI, V.C.B.; LAVORENTI, A.; TOMISIELO, V.L.; REGITANO, J.B. Sorção e dessorção de glifosato em solos com distintos níveis de fósforo. Scientia Agricola, Piracicaba, v. 60, n. 1, p. 175-180, 2003.

SANTOS, D.P.; BRAGA, R.R.; GUIMARÃES, F.A.R.; PASSOS, A.B.R.J.; VALADÃO SILVA, D.; SANTOS, J.B.; NERY, M.C. Determinação de espécies bioindicadoras de resíduos de herbicidas auxínicos. Revista Ceres, Viçosa, v. 60, p. 354-362, 2013. 
SANTOS, M. V.; FREITAS, F. C. L.; FERREIRA, F. A.; VIANA, R. G.; TUFFI SANTOS, L. D.; FONSECA, D. M. Eficácia e persistência no solo de herbicidas utilizados em pastagem. Planta Daninha, Viçosa, v. 24, n. 2, p. 391-398, 2006.

SILVA, A. A.; VIVIAN. R.; OLIVEIRA Jr. R, S. Herbicidas: comportamento no solo. In: SILVA, A. A.; SILVA, J. F. Ed. Tópicos em manejo de plantas daninhas. Viçosa: Universidade Federal de Viçosa, 2007. p.189-248.

THILL, D. Growth regulator herbicides. In: THILL, D. Herbicide action course. West Lafayette: Purdue University, 2003. p. 267-291.

YAMASHITA, O.M.; BETONI, J.R.; GUIMARÃES, S.C.; ESPINOSA M.M. Influência do glyphosate e 2,4-D sobre o desenvolvimento inicial de espécies florestais. Scientia Forestalis, Piracicaba, v. 37, n. 84, p. 359-366, 2009. 